\title{
Fund Allocations for Information Resources in China's Key Universities
}

\author{
Jin-Chuan Ma \\ Translated by Sha Li Zhang
}

\begin{abstract}
Libraries in China's key universities will be the bases for collecting and managing information resources that serve their own user communities and will be an integral part of information resources for the China Academic Library and Information System as well. Allocating adequate materials funds from the university operational budget is essential if these libraries are to adequately support their learning and research communities. This article examines the current situation these libraries are facing and makes proposals for changes.
\end{abstract}

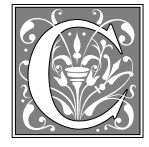

hina has one hundred and seven key universities. The functions and characteristics of these universities are in one way or another similar to those of research universities in the Western world. They are centers in producing high-quality scientists and researchers for the country. Currently, sixty-one key universities have been selected to participate in Project 211 , an initiative funded by the State Development \& Planning Commission of China to improve the quality of education, research, management, and institutional efficiency. ${ }^{1}$ These key universities will play important roles in catching up with their counterparts in the world in the beginning of the next century. One of the goals of Project 211 is to establish a modernized academic library and information system through the China Academic Library and Information System (CALIS), a subset of Project 211. In that capacity, CALIS has responsibility for developing three-tiered information resources' networks for academic libraries at the national, regional, and campus levels. Libraries in these key universities will be the bases for collecting and managing information resources that serve their own user communities and will serve as an integral part of information resources for CALIS as well. Therefore, it becomes very important to allocate sufficient funds for information resources in these universities.

\section{Familiar Scenario 1: Continuing Decline of Library Resources}

Since the mid-1980s, with continuing increases in materials pricing, library collections in China's key universities have declined dramatically. First, many libraries have substantially reduced the number of copies of instructional monographs in the Chinese language. Before the early 1980s, these libraries had the luxury of keeping more than ten copies of the same

Jin-Chuan Ma is a Deputy Director of Nanjing University Library in Jiangsu Province, People's Republic of China; e-mail: majinchuan@nju.ecu.cn. Sha Li Zhang is Head of Technical Services at Wichita State University; e-mail: zhang@twsuvm.us.twsu.edu. The original version of this paper appeared in the Journal of Academic Libraries 16, no.2 (1998): 26-28. 
title. However, at present, libraries can afford to keep only one or two copies of such types of materials. ${ }^{2}$ Second, due to continuing price increases of foreign materials (in languages other than Chinese), these types of materials have become major candidates for cancellation among the reduced collections, even though they are very important to graduate programs and research projects. Third, among these university libraries, foreign journal subscriptions have experienced several major cancellations in past years. At present, the total number of foreign journals is one third of what it was in the mid-1980s. The situation of foreign monographic collections has become even worse. The total number of foreign monographic titles purchased now is one tenth of what is was in the mid-1980s. ${ }^{3}$

With rapid developments in science and technologies, the number of publications in these fields also has increased at a fast rate. A statistical report provided by the China Books Import and Export Company indicates that the rate of new journal titles in science and technology is two percent annually. ${ }^{4}$ In the past ten years, the number of journal articles cited by Science Citation Index increased 13 percent and the number of those reported by the Index to Scientific and Technical Proceedings increased 66 percent. New journals are very important sources for the latest development in science and technology, but China's key university libraries cannot afford to subscribe to them. The lack of adequate funds has widened the gap between the increased number of publications in science and technology and the libraries' collections in these two fields.

For a long time, information resources funds at these key university libraries came from the respective institution's operational budget, about five percent annually. This percentage has not increased for a long time. With continued soaring prices of foreign materials and the absence of additional or new funds from the university, library resources will continue to decline.

\section{Familiar Scenario 2: Declining Collections of Foreign Materials}

Foreign materials are indispensable in keeping the university community informed about the latest scientific and technological developments in the world. Key universities are putting more emphasis on scientific research through their academic disciplines. Without adequate access to foreign materials in science and technology, it is impossible to conduct high-quality research.

Since the late 1970s, the number of publications by faculty and graduate students in these key universities has continued to increase. Most of these publications have appeared in major scholarly journals at national and international levels. One of the contributing factors to this endeavor was the government's financial support in acquiring foreign materials for these university libraries. Each year, the Beijing-based China Research Institute of Science and Technology Information provides the number of articles published in science and technology journals by faculty and graduates in key universities. The institute ranks each key university accordingly; it indicates that the top ranking universities often have rich information resources in their libraries. A similar correlation exists between research outcomes and library resources in major research universities throughout the world. ${ }^{5}$

In terms of research outcomes, there is still a gap between key universities in China and their counterparts in the rest of the world. In 1995, the total number of research publications cited by Science Citation Index, Index to Scientific and Technical Proceedings, and Engineering Index from Taiwan University was equal to the total of those by researchers from the top three universities in China. This phenomenon may not mean that these researchers were less capable, but it may indicate that researchers in these universities had less access to information resources than their counterparts in Taiwan University did. A rich library collection is an important component of the research 
process. Many scholars in China's key universities have had significant accomplishments in research projects when they visited research universities abroad where they had access to the latest information resources and facilities in science and technology. In the scholarly communication process, scientists tend to report and communicate their discoveries / findings through science journals. In the United States, some major research university libraries subscribe to more than 10,000 journals. ${ }^{6}$ Taiwan University Libraries subscribe to more than 20,000 journals. ${ }^{7}$ Hong Kong Science and Technology University also subscribes to more than 10,000 journals. ${ }^{8}$ In 1995, seventy-one major universities in China subscribed to only 6,000 foreign journals and newspapers. Due to the lack of consistent and continuing coverage of foreign journals, researchers in these universities have difficulty thoroughly reviewing literature, keeping track of new developments and trends in a timely manner, engaging in new research projects, and verifying and evaluating research undertakings. Sometimes this results in duplicate research projects. Moreover, without adequate resources such as foreign journals, it is impossible to update the curriculum in these universities. Obviously, the decline of foreign journal subscriptions has had a severe impact on the graduate programs and research activities in China's key universities.

\section{Problematic Perceptions}

For a long time, the percentage of library materials funds has been about five percent of the university's operational budget. This allocation is based on the Library Provisions for Institutions of Higher Learning issued by the State Educational Commission. ${ }^{9}$ The total amount of the operational budget to each university provided by the commission is based on the number of enrolled undergraduate and graduate students. In theory, because undergraduate students consist of a large part of the student body, the university's operational budget should be used mainly to support instructional programs and resources. However, in many key universities, the library spends over 70 percent of its materials funds on expensive research journals. Thus, less than 30 percent of the funds are used to purchase instructional materials. Students have expressed dissatisfaction about the situation. ${ }^{10}$

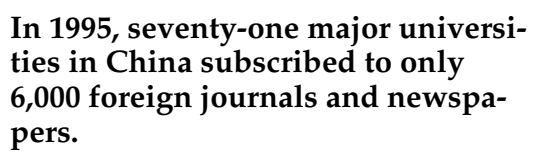

In recent years, many key universities have been able to obtain a large amount of research funds from various grants in addition to their normal operational budget. In some cases, the research funds are almost equivalent to their operational budget. It is understood that the research funds should include a portion the library can use to purchase or subscribe to materials to directly support research projects. In practice, thousands of dollars have been spent on purchasing equipment, but not a single penny was allocated for library resources. Libraries have requested a small amount of the research grants in the past, but without success. Researchers are used to relying on library resources without thinking about funding for them.

In some key universities, the materials purchased by the funds from research grants were often kept in departmental libraries administered by each individual department or school. In a few cases, these materials were even being kept in researchers' offices. This practice not only causes duplicate acquisitions and subscriptions within the institution, but also prevents users from other departments or schools from using these materials. Such a practice is still in existence and is not being addressed adequately.

\section{Proposals for Changes}

For the library to respond favorably to the teaching and research needs of its user community, the aforementioned situations need to be changed. The following proposals should serve as a framework when changes are being made: 


\section{Establish a Deducting-percentage System}

With limited resources, many research universities in the world have established a system that allows the library to have a certain percentage of research funds for acquiring research-oriented materials. ${ }^{11}$ This practice has merit in terms of China's situation.

According to a data provided by the China Research Institute of Science and Technology Information, in 1995, researchers in China's universities contributed 17,921 journal articles through funded projects. ${ }^{12}$ This was 75 percent of the total number of journal articles published that year. There is a connection between the quality and quantity of research outcomes and the level of library resources. Therefore, it is reasonable for the library to request a certain percentage of research funds for acquiring information resources within the university. These materials directly support research projects. An additional five percent should be allocated from the tuition income for library resources.

\section{Enhance Integrated Resources Develop- ment}

When it is time for academic libraries to move toward integral resources development at regional and national levels, there will be an urgent need to improve the management of materials funds and resources within each key university.

Historically, there have been two types of libraries within a university in China: university libraries and departmental libraries. Currently, there are more than 5,000 departmental libraries; a large of number of them are in key universities. These departmental libraries are funded and administered by individual departments or schools. Acquisitions and catalogs are maintained at the department level. Such an arrangement has its own merit: small, but specialized, collections housed together provide physically convenient access and flexible checkout procedures. The department owns these materials. Faculty and graduate students in the department like the system, but because there is no online catalog, it is impossible for users in other departments to share the materials. In some cases, due to inadequate checkout procedures, some faculty checked out materials and kept them in their office forever. Some university libraries attempted to improve or change the situation but were met with resistance from faculty and department heads. Also, the university administration did not provide support for the integration of resources.

With the development of modern information technologies, it is easier than before to engage in cooperative acquisitions, develop online catalogs, and share information resources. In such an environment, it would be more effective to have the university library oversee materials funds, human resources, and collections within a university. The departmental library would become a branch library based on subject disciplines. Last year, when Ms. Rita Scherrel, an associate university librarian at the University of California at Los Angeles visited the Nanjing University Library, she shared her experience in implementing this management model. In China, the university administration is the key to promoting and implementing this model.

\section{Revise the Existing Provisions}

In 1987, the State Educational Commission issued "Library Provisions for Institutions of Higher Learning." According to these provisions, the university administration should allocate five percent of its annual operational budget to the library for acquiring information resources. Since then, the provisions have enabled the library to acquire adequate funds from the university administration. Furthermore, the provisions encourage the university administration to allocate additional funds from various research grants and other incomes to the library for information resources. These funds also should be administered by the library. However, this part of the provisions has never been realized and practiced in key 
universities.

In the past decade, there have been rapid changes in information technology, higher education, university budgets, and materials pricing. Therefore, it is necessary to revise the provisions accordingly so that they provide guidelines for collecting adequate library collections. Universities granting graduate degrees have obtained more research funds, doctoral program grants, and other incomes in addition to their normal operational budget. These funds consist of a large portion of the university's total budget. At the same time, graduate students and researchers in key universities want more library materials than those in other universities. Libraries in these key universities have voiced their demands for more materials funds from the university administration. Nanjing University administration has twice decided to allocate an additional three to five percent of funds from research funds to the library. However, these decisions have never been put into practice, primarily because of the lack of government provisions. Therefore, it is necessary to revise the current provisions, which will allow the university to allocate sufficient funds from various incomes to the library. In this way, the library will be able to serve its community with consistent and continuing resources.

\section{Conclusion}

Library resources that are used to support teaching and research in key universities must be provided on a regular basis. The funds for acquiring such resources must be regulated and protected by government provisions. These provisions should be authoritative, regulative, and enforceable. Moreover, an effective system should be established to regularly update the provisions.

\section{Notes}

1. Qiang Zhu, "Increasing the Pace of an Integral Library System in China: Moving toward the Twenty-First Century," College \& Research Libraries 59 (Mar. 1998): 169-76.

2. Xiao-Ming Li, "Major Concerns on Library Resources Development in Academic Libraries," China Education Newspaper, Aug. 19, 1993, section 2.

3. Academic Libraries Resources Development Project Group, " Research and Recommendations on Establishing the China Academic Library and Information System (CALIS)," in Research on Humanities and Social Sciences (Beijing, P.R. China: State Educational Commission, 1995), 10.

4. Ji-Yuan Ye, Introduction to Core Journals (Nanjing, P.R. China: Nanjing Univ. Pr., 1995), 15.

5. Yu Hou and Xiao-Yuan Hu, "Canadian Universities Evaluate Libraries in China," Journal of Academic Libraries 15, no. 2 (1997): 72-74.

6. Project 211 Information Resources Sharing System Development (draft) (Beijing, P.R. China: Peking University, 1996), appendix.

7. Wei-Ping Yang, Han-Yun Shi, and Yi Li, eds., Colleges and Universities in Taiwan (Hong Kong: Han-Rong Publishing, 1993), 9.

8. Introduction to Hong Kong Science and Technology University (Hong Kong: Hong Kong Science and Technology University, 1995), 18.

9. Library Provisions for Institutions of Higher Learning (Beijing, P.R. China: State Educational Commission, 1987).

10. Feasibility Studies on the China Academic Library and Information System (Beijing, P.R. China: Peking University, 1996), 4.

11. K. A. Brandt, Jerry J. Campbell, and W. F. Fryant, "Reflection on Reference Services," Journal of American Society for Information Science 47, no. 3 (1996): 210-16.

12. 1995 Annual Report on Statistics and Analysis of China's Science and Technology Publications (Beijing, P.R. China: China Research Institute of Science and Technology Information, 1996), 141. 